\title{
Claves y retos de la documentación digital en televisión
}

\author{
Por Teresa Agirreazaldegi-Berriozabal
}

Resumen: La televisión se está digitalizando, y con ella el trabajo de archivo. La digitalización del patrimonio conservado está siendo mucho más lenta y requiere financiación pública extraordinaria. Este hecho junto con los nuevos desarrollos tecnológicos propician la apertura de los grandes archivos (BBC, Ina, $B \& G$, etc.) al público en general. En las emisoras, la digitalización y los sistemas de gestión de contenidos multimedia (MAM) ofrecen nuevas herramientas y generan un nuevo contexto de trabajo, tanto para los usuarios del archivo como para los documentalistas.

Descriptores: Archivos de TV, Documentación

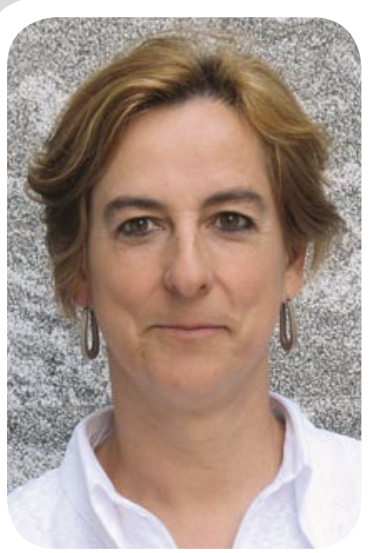

Teresa Agirreazaldegi Berriozabal, obtuvo una maitrise y un DESS en documentación por la Universidad Paris VIII y es doctora en periodismo por la Universidad del País Vasco, donde ejerce la docencia desde 1990. Fue documentalista en La documentation française y en la empresa Infodoc SA; responsable del centro de documentación de Emakunde y jefa de documentación en Euskal Telebista. Ha publicado varios libros y artículos sobre documentación y televisión como El uso de la documentación audiovisual en los programas informativos diarios de televisión, Dokumentazio Informatiboa (Documentación informativa) y Dokumentazioaren hasi-masiak gazte informatzaileentzat (Principios de documentación para informadores juveniles).

audiovisual, Digitalización, Archivo abierto, Centros de documentación, Televisión, Gestión de contenidos multimedia, Usuarios.

\section{Title: Digital documentation: tools and challenges for television}

Abstract: Television is becoming digital, as are TV archives and archival research. Digitisation of previously archived footage is a slow, expensive process that requires significant public funding. This fact, together with new technological developments, favours the opening of major archives to the general public (BBC, INA, B\&G, etc.). For TV stations, digitising and media asset management (MAM) systems offer new tools and generate a new work environment, both for reporters and archival research.

Keywords: TV archives, Audiovisual documentation, Digitising, Open archive, Documentation centres, Television, Multimedia content management, Users.

Agirreazaldegi-Berriozabal, Teresa. "Claves y retos de la documentación digital en televisión”. En: El profesional de la información, 2007, septiembre-octubre, v. 16, n. 5, pp. 433-442.

DOI: 10.3145/epi.2007.sep.05

\section{Introducción}

DESPUÉS DE MUCHAS PROMESAS, LA DIGITALIZACIÓN COMIENZA a ser una realidad en las emisoras. Tal y como ha sucedido en otros medios de comunicación social, la digitalización de la televisión viene de la mano de la digitalización de los procesos productivos: se graba $y$ se emite en digital, se digitalizan las redacciones de informativos, deportes y programas; antes había sido el turno de postproducción y grafismo. El archivo se integra plenamente en esta dinámica.

En las emisoras se implantan sistemas de gestión de procesos y contenidos que proveen de herramientas para, de forma rápida y eficiente, organizar ficheros de vídeo y facilitar la gestión asociada al archivado, la reutilización y la distribución de los contenidos digitales y multimedia. Crece la importancia del archivo digital, debido a la orientación a la reutilización de contenidos y a la integración con las plataformas de servicios interactivos. El trabajo de los documentalistas evoluciona, ayudado por nuevas herramientas. Y los tradicionales usuarios de la documentación audiovisual pueden consultar y recuperar documentos de forma autónoma.

La nueva producción es digital, pero ¿qué sucede con los fondos de archivo? La digitalización es el único modo de asegurar su preservación, pero conlleva grandes costes. En esta encrucijada puede ser el momento para redefinir el papel de los archivos audiovisuales como garantes del patrimonio audiovisual. 


\section{La gestión de contenidos audiovisuales digitales: los sistemas MAM (Media asset management)}

Desde sus primeras apariciones en 2000, y tras una fase de desilusiones y cambios, los sistemas de gestión de contenidos (MAM) fueron la estrella del IBC 2006 (International broadcast convention) cita anual de la industria audiovisual europea, que agrupa a creadores y proveedores de contenido, equipamiento, profesionales, técnicos, asociaciones, etc.

Un centro de gestión de contenidos es un conjunto de recursos que permite la gestión de los activos audiovisuales para su transmisión por redes diversas. Cumple las siguientes funciones: reutilización de contenidos; distribución, emisión, archivo y soporte a actividades de producción. Para desarrollarlas es necesario integrar tecnologías diferentes y complementarias: diferentes formatos de vídeo (SDI, mpeg2, mpeg1, mpeg4, DV, etc.), redes de transmisión, videoservidores, browsing, búsqueda, consulta y edición en baja calidad, archivo digital y automatización (Giménez, 2003).

El flujo de información sigue los siguientes pasos:

- Ingesta: se trata de la adquisición de la información procedente de las fuentes audiovisuales, convirtiéndola en datos en el formato de trabajo elegido, con una o varias calidades (mpeg1, mpeg2, mpeg4, etc.). La ingesta está basada en la grabación simultánea de la señal en servidores, en alta y baja resolución, lo que requiere una perfecta sincronización, generalmente basada en el código de tiempos y en la distribución de una señal de referencia a todos los equipos del sistema. En este estadio se definen los parámetros básicos de precatalogación automática que facilitarán la labor posterior de documentación.
- Almacenamiento: consiste en alojar en los servidores, adecuadamente dimensionados, los datos obtenidos en el proceso de ingesta. Un servidor de base de datos gestionará los metadatos asociados a los ficheros almacenados.

- Catalogación de los recursos que haga recuperable la información almacenada. Se desarrolla a dos niveles, uno básico y parcialmente automatizable y otro avanzado, incluyendo toda la información necesaria para la correcta recuperación. Recoge tanto información de contenido como técnica y administrativa, generándose un storyboard basado en cambios de plano, en intervalos temporales, etc., dependiendo de la complejidad y la precisión de la aplicación. En la pantalla de trabajo se presenta tanto la información escrita como el propio documento audiovisual, con ajuste de precisión de cuadro, de modo que en el caso de los originales de cámara (o brutos) se puedan desechar los fragmentos que no interese conservar.

- Búsqueda, recuperación y edición, es decir, procesamiento de la información recuperada. A partir de una interfaz sencilla y amigable se pueden realizar consultas y recuperar los documentos audiovisuales, manejando un formato de fichero único, intercambiable y preparado para circular por la Red, sin la necesidad de realizar copias en diferentes formatos y evitando los equipos para visualizar y seleccionar. El usuario consulta, visiona y selecciona interactivamente desde un único puesto, optimizando flujos de trabajo, tareas, tiempo y equipamiento.

Desde un PC multimedia el usuario podrá realizar todas las tareas utilizando tecnología avanzada de búsqueda, consulta dinámica, generación de una copia de alta resolución del material seleccionado y envío mediante procedimientos informáticos convencionales a la edición no lineal de altas prestacio- nes para su procesado final. Una vez realizadas las tareas de preselección y edición más elementales, se lleva a cabo el conformado en alta resolución del trabajo de edición realizado en baja calidad, un complejo proceso informático de tratamiento de datos, con filosofía similar a la clásica edición off line. Como formato se utiliza mpeg1 o mpeg4 en baja resolución (calidad visionado) y mpeg 2 o DV en alta resolución (con calidad profesional); lo importante es que el fichero seleccionado sea único para el mismo nivel de calidad.

Se requieren también equipos de edición de alta eficacia, que incorporen prestaciones de edición en tiempo real, 2D y 3D, cámara lenta, corrección de color, composición y titulación, etc. Así como capacidad para publicar en la web en formato legible por reproductores estándar (Windows media player, Real video o Quicktime).

- Archivo: el hardware de almacenamiento lo componen el servidor de vídeo de alta y baja resolución, el servidor web, el robot de cintas y el servidor de bases de datos. En función del volumen de información que se vaya a manejar es necesario parametrizar la capacidad o número de horas de los servidores, en una arquitectura escalable que permita el crecimiento progresivo.

- Tráfico: es fundamental definir correctamente los flujos de trabajo y conocer en cada momento qué y cuánta información circula por la red. Un módulo de gestión de tráfico será el encargado de facilitar información estadística y administrativa sobre este aspecto de cara a optimizar el sistema.

Como vemos, todo el material audiovisual se digitaliza y almacena en diferentes calidades, simultáneamente y generando a la vez los metadatos previos y posteriores, de modo que con una potente herra- 
mienta de trabajo, que consta de diferentes módulos, podamos acceder a los contenidos, seleccionarlos y editarlos, tanto desde un punto local como remoto, con más o menos privilegios administrativos.

El material editado y postproducido se encaminará a la emisión. Una parte de las grabaciones pasará a un archivo definitivo y otra será borrada, liberando espacio del servidor. Documentación alimenta el sistema con metadatos, pero además el propio sistema va incorporando los metadatos que marcan el procesamiento, la vida de la grabación y su relación con otras grabaciones.

\section{La documentación dentro de los sistemas de gestión de contenidos}

Un sistema $M A M$ remodela la organización de tareas e implica que todos los eslabones de la cadena compartan una misma visión global y funcional de la emisora. Por ello, no pueden ser paquetes estándar cerrados, ya que las estrategias y tácticas puestas en práctica varían de una emisora a otra.

Los servicios de documentación en televisión difieren en dimensión, organización interna, funciones y dependencia orgánica (Agirreazaldegi, 1997). La primera cuestión que plantea la elección de un sistema $M A M$ es en qué lugar de la cadena se sitúan estos servicios de documentación. No hay una respuesta única, encontramos dos presupuestos organizativos sustancialmente diferentes que se corresponden con tradiciones diferentes y que otorgan la prioridad en el archivo bien al material emitido, bien a los originales de cámara (o brutos).

En los servicios de documentación que toman los originales como base, la digitalización viene a resolver los grandes problemas que han sufrido durante años, como eran la pérdida de materiales que nunca llegaban a documentación, la tar-

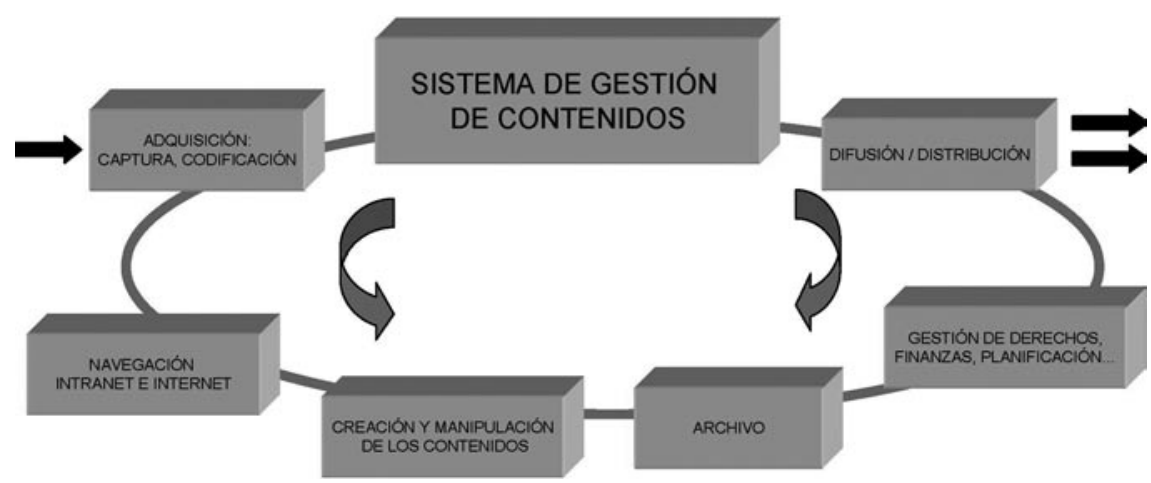

Figura 1. Esquema de un sistema de gestión de contenidos (media asset management)

danza con que se entregaban y la falta de datos sobre las grabaciones audiovisuales, lo que dificultaba en gran medida su selección y análisis. Todo ello repercutía en la escasa valoración de la documentación y del trabajo de los documentalistas.

Hoy en día algunas de estas televisiones, como por ejemplo Telemadrid, colocan el servicio de documentación al comienzo del proceso, haciéndolo responsable de la ingesta de datos (grabaciones audiovisuales) procedentes de la producción y de sus consiguientes metadatos de identificación. En este estadio se requiere rapidez y disponibilidad, ya que las grabaciones son la materia prima del periodista de informativos y de otros profesionales, quienes las utilizarán para componer las noticias (así como titulares, cabeceras, gráficos, etc.). En el proceso se irán añadiendo metadatos y se producirán diferentes versiones. Si el trabajo de la redacción culmina con la emisión, para Documentación el trabajo más importante será decidir qué grabaciones deberán conservarse y dónde, es decir, en el archivo temporal o definitivo. Para tener una cierta perspectiva, esta selección se lleva a cabo al día siguiente a la entrada de los datos. El material seleccionado será catalogado, mientras que el resto será borrado de los servidores.

Otras emisoras, como Televisió de Catalunya (TVC), basan su archivo en el material emitido, con- servando además una estricta selección de originales. En estos casos la digitalización no ha supuesto un vuelco en los flujos de información. Documentación sigue operando con las grabaciones audiovisuales una vez producida la emisión. Todo el material emitido, junto con sus metadatos asociados pasa automáticamente a un servidor, donde los documentalistas proceden a su análisis, completando y normalizando los datos. Por otra parte, todo el material utilizado para la confección de los programas -los originales de cámara, las señales de agencia, las señales de intercambio, etc.- es revisado por los documentalistas para ser seleccionado -en su totalidad o en una parte- o descartado. En caso de ser seleccionado, los documentalistas completan sus metadatos y establecen las correspondencias entre estos originales y los editados donde han sido utilizados.

Saber que todo lo emitido (es decir, todo lo importante desde el punto de vista periodístico y editorial) es sistemáticamente conservado y perfectamente documentado hace que la tarea de selección de originales sea relativamente sencilla y rápida: únicamente habrán de conservarse aquellos materiales que aporten riqueza documental, o cuya importancia (informativa, histórica, cultural) haga conveniente guardar la grabación en su totalidad. También se tomarán en consideración las peticiones de los jefes de sección o de los propios periodistas 
para conservar algún original en concreto.

\subsection{La digitalización en Tele- madrid}

Comienza en 1999 en la redacción de informativos y, desde ese momento, el archivo se responsabilizará de los flujos y procesos digitales. El lugar del archivo se descentraliza, deja su lugar físico, deviene un proceso dinámico, una actividad integrada en el proceso de trabajo digital, operando con todos los lugares de producción de la compañía. Los MAM marcan el final de los compartimentos separados de documentalistas, periodistas y productores. En este flujo de materiales y metadatos, el documentalista audiovisual se ocupa de la selección y la catalogación. Se encarga de asegurar la preservación, la gestión del flujo digital y garantiza el equilibrio entre las diferentes partes implicadas en la producción; el documentalista es una guía, pone orden, organiza el caos informativo generado en el MAM. A través de este completo (y cada vez más automatizado) proceso del flujo de datos, es de importancia vital la existencia de una figura que compruebe que los procesos se hayan realizado satisfactoriamente, que el metadato asociado es coherente y que no se generan errores sistemáticos durante el proceso (Vázquez, 2006).

La integración del documentalista en el proceso de producción es positiva porque está en contacto directo con periodistas, productores, editores, etc.; aunque a veces su trabajo se confunda con lo que sería la tarea tradicional del ayudante de producción: racionaliza los flujos de trabajo, comprende el objetivo de la producción; selecciona imágenes para el archivo temporal o permanente y las cataloga.

\subsection{La digitalización en $T V C$}

Comienza en informativos y deportes en 2003, y de programas un año más tarde. El sistema $M A M$

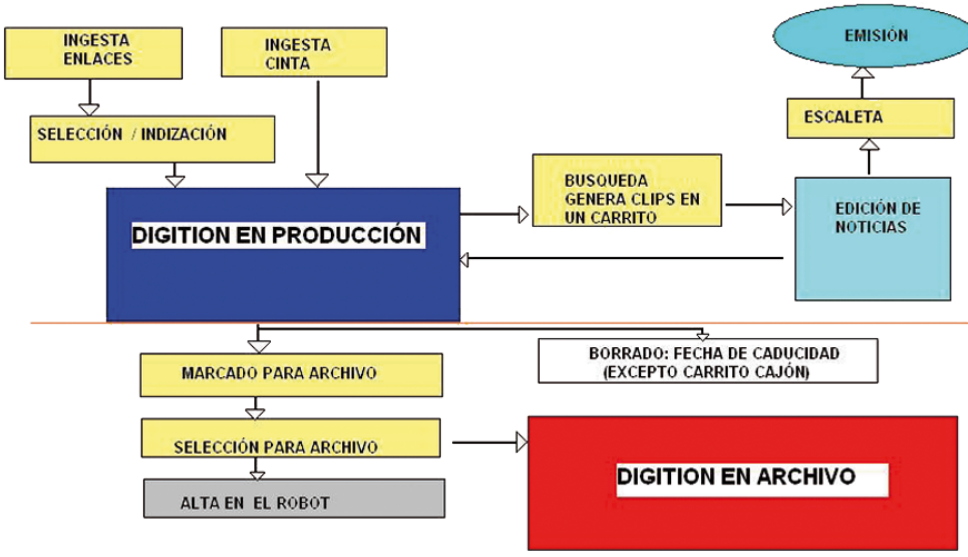

Figura 2. Esquema del sistema MAM de Televisió de Catalunya

implantado tiene dos áreas bien definidas: una de producción y otra de archivo. La primera comprende todos los pasos desde la ingesta a la emisión. El material emitido se vuelca automáticamente a los servidores de archivo, donde será catalogado; los originales serán revisados por los documentalistas para su selección o borrado.

Para cada tipo de programa y material se ha parametrizado a qué archivo y dominio irá, qué metadatos deberá incorporar y qué circuito seguirá en el archivo (documentación, copia de seguridad, etc.); las acciones posibles son aceptar, rechazar o editar antes de aceptar el material (Conesa, 2005).

\section{Las funciones del documentalista audiovisual digital}

Hemos visto que los sistemas de gestión de contenidos replantean los flujos de información y la organización del trabajo en las emisoras; también en lo que respecta al servicio de documentación. El documento ha cambiado; desde el punto de vista de las técnicas digi- tales un asset es una combinación estrecha de datos de contenido (imágenes, sonidos, textos, gráficos, etc.) con metadatos (datos que acompañan y caracterizan los datos de contenido). En digital todos los contenidos y todas las formas son representados por 0 y 1 ; por ello es importante pegar etiquetas que califiquen, identifiquen y sitúen los datos. Los metadatos son elementos fundamentales para el intercambio y la utilización de datos digitales.

Los metadatos no son patrimonio de Documentación, son acumulativos y se enriquecen a través del proceso que sigue la grabación audiovisual desde su incorporación al sistema, la generación de diferentes versiones, los controles de calidad, la emisión, etc. hasta su instalación en el servidor o en la librería robotizada.

Como ya ocurrió con la fotografía, la digitalización de las grabaciones audiovisuales y su acceso a través de servidores está cambiando el análisis documental. Lejos de las promesas milagrosas de comienzos de los años 90, las nuevas herramientas de ayuda a la indización se 
integran facilitando, sistematizando o completando la labor de los documentalistas audiovisuales. Son una ayuda, y permiten al documentalista consagrarse a tareas de interpretación y de anotación. La tarea de análisis sigue siendo necesaria, ya que la percepción de un documento llama a todo un universo cultural, social y personal.

Pero ahora, el análisis ha de identificar y nombrar para posibilitar la búsqueda, no ha de describir. La función descriptiva/narrativa del análisis documental desaparece. Se titula la noticia, si es necesario se resume el argumento y se procede a identificar, en el propio documento, los elementos visuales, audiovisuales y sonoros significativos. El documento se segmenta y muestra sucesivos fotogramas; se hace accesible a través de los rótulos que contiene, de los textos elaborados por los periodistas o del audio.

La estructura del flujo audiovisual está fuertemente transmitida por la imagen, pero el sentido por la palabra. En el análisis del sonido intervienen la detección de los sonidos, la música, la palabra, los ruidos particulares, la segmentación entre los diferentes locutores, el reconocimiento del locutor, la trascripción de la palabra. El reconocimiento del habla simplifica los procesos de catalogación de informativos, no sólo de los programas sino también por ejemplo, los discursos de los políticos.

María-Luisa Vázquez (2006) señala como tareas específicas del documentalista audiovisual en el nuevo entorno digital:

- La generación de documentos electrónicos específicos para archivo, reutilizando otros existentes. A menudo el archivero genera información, hace compilaciones, edita imágenes pensando en el archivo permanente, aprovechando búsquedas complejas ya realizadas y con el objetivo de facilitar las

\section{"El desplazamiento de la responsabilidad de las búsquedas del documentalista al periodista, traerá consigo nuevas funciones de guía y formación en los sistemas de recuperación"}

búsquedas y el trabajo posterior de periodistas o editores.

- La preservación de imágenes para el archivo permanente. El documentalista selecciona empleando criterios archivísticos que tienen en cuenta la reutilización o el patrimonio, aspectos en los que no piensan periodistas ni editores.

- El documentalista lleva a cabo una catalogación especializada, utilizando pautas rigurosas. La digitalización y las nuevas técnicas de catalogación automatizada (captura de keyframes, reconocimiento del audio y texto, o reconocimiento de imágenes) han simplificado el proceso de indización y las tareas de catalogación. Pero, aún así, sigue siendo necesario completar los metadatos originados por producción y el trabajo del documentalista audiovisual especializado sigue siendo necesario. Gracias a su experiencia podrá, por ejemplo, describir el vídeo previendo las peticiones.

Ninguna de las funciones mencionadas es realmente nueva; salvo, quizás, la labor de edición que en muchas compañías se delegaba en los operadores de vídeo. Lo que realmente ha variado es la forma o el momento de llevarlas a cabo, su importancia y con ella el aumento de la visibilidad del servicio de documentación y del trabajo del documentalista en la empresa.

En un futuro, algunas tareas del servicio de documentación desaparecerán, especialmente las que tienen que ver los soportes analógicos, las copias, el movimiento en los depósitos, el etiquetado, el préstamo, etc. Otras se verán reforzadas, potenciadas y facilitadas por el nuevo entor- no digital, es el caso de las funciones de apoyo a las previsiones informativas. Preparar materiales con antelación y ponerlos a disposición de los interesados puede convertirse en una de las tareas clave de la documentación en un futuro. También el papel normalizador de la documentación puede salir reforzado, manteniendo el libro de estilo del medio de comunicación. Algunas funciones variarán sensiblemente, como la búsqueda de documentación audiovisual, que disminuirá en número pero no en complejidad e importancia. Además, tal y como ya ha ocurrido en la prensa escrita, el desplazamiento de la responsabilidad de las búsquedas del documentalista al periodista, traerá consigo nuevas funciones de guía y formación en los sistemas de recuperación; debería suponer también una implicación completa de la documentación en el diseño de estos sistemas.

\section{El periodista como recuperador de la documentación audiovisual}

El usuario "se ha colado" en los servicios de documentación de televisión, uno de los últimos reductos donde la difusión de la información y de los documentos requería obligatoriamente la intermediación del documentalista. Buscar en bases de datos referenciales, en largos y complejos registros, para después solicitar soportes en ventanilla, no tuvo mucho éxito entre los usuarios de la documentación audiovisual; era mejor confiarse al especialista desde el primer momento.

La web, sin embargo, ha cambiando completamente el acceso a la información y la digitalización 
de la televisión transforma el trabajo del periodista; buscar y recuperar documentación audiovisual para diseñar la noticia forma parte de su trabajo. Los nuevos sistemas digitales le permiten localizarla y recuperarla de forma rápida y eficaz. El periodista puede ser (y va a querer ser) autónomo para resolver muchas necesidades sencillas.

Pasamos de una recuperación lenta, muy mediatizada, que requería una descripción detallada de los documentos audiovisuales, la movilización de soportes y la disponibilidad de equipos diversos, a una visualización y recuperación inmediata del documento (inmaterial) por parte del usuario final. La descripción por estratos y el acceso al clip, por ejemplo, se adaptan bien a la forma de utilizar la documentación en los programas informativos, caracterizada por un empleo intensivo de planos o secuencias muy cortas.

Es preciso que Documentación se adapte al lenguaje periodístico y guarde las informaciones confeccionadas por la redacción (guiones, escaletas, etc.) ya que el periodista, el usuario final, ha de poder buscarse y reconocerse. En este sentido, el trabajo del documentalista ha de consistir en completar metadatos, aportando normalización y perspectiva histórica.

María-Luisa Vázquez (2006) llama la atención sobre la superabundancia de grabaciones y diferentes versiones que se generan en los sistemas digitales ("hasta el punto que los $M A M$ podrían llegar a morir de éxito"); y señala que en el propio sistema se deberán desarrollar fórmulas de asistencia a la recuperación, por ejemplo, facilitando la búsqueda de documentos temáticos, ordenando los clips, agrupándolos lógicamente, evaluándolos de forma previsible y fácil; en definitiva, designando la mejor opción ante una búsqueda, ayudando a valorar no sólo cuantitativa sino también cualitativamente, y todo ello teniendo en cuenta la idiosincrasia del material catalogado.

Los sistemas de interrogación y navegación han de permitir al periodista:

- Buscar de una forma sencilla e intuitiva. Lo que significa, entre otras cosas, poder utilizar "su lenguaje" y "sus códigos".

- Recuperar rápidamente, con un número de respuestas adaptado a su necesidad de información. Por ejemplo, para programas informativos diarios esto significa, en la mayoría de los casos, pocas respuestas y documentos cortos, ya que se utilizan pocos segundos de cada grabación.

- Posibilidad de ampliar el resultado de la búsqueda a través de un simple clic: el sistema ha de ofrecer más respuestas sobre los mismos criterios de búsqueda: cercanos, otros nuevos asociados, etc. Esto requerirá el desarrollo y la mejora de los lenguajes documentales y de los sistemas de representación del conocimiento.

- Recuperar la información más pertinente con un nivel de respuesta adaptado al tipo de demanda; en programas informativos quiere decir encontrar imágenes y planos definidos, pero también noticias concretas o imágenes que sirvan para ambientar temas (Agirreazaldegi, 2006).

Sin duda, conocer las necesidades y el modus operandi de los usuarios de la documentación audiovisual va a ser fundamental a la hora de diseñar adecuadamente los nuevos sistemas digitales. En un futuro los propios sistemas deberán facilitar la información estadística y administrativa que permita su evaluación y su mejora.

\subsection{El uso de la documenta- ción audiovisual}

Pocos estudios han analizado las necesidades y las formas de trabajo de los usuarios de la documen- tación audiovisual, sin embargo, ha de ser este conocimiento el que guíe el trabajo documental y el diseño de los nuevos servicios digitales.

En nuestra investigación sobre el uso de la documentación audiovisual en los programas informativos diarios (Agirreazaldegi, 1997), comprobamos que en torno al $40 \%$ de las noticias emitidas en los programas informativos diarios emplean documentación audiovisual; y que este porcentaje aumenta en las noticias que abren los programas y las secciones informativas. Esto se debe a que las noticias importantes son tratadas con mayor profundidad y tienen mayor duración, empleando la documentación audiovisual especialmente para contextualizar, explicar y completar la información.

En general, se hace uso de la documentación audiovisual en las noticias de las cuales no se tienen grabaciones de día (en nuestro estudio un 14\%) pero, todavía en mayor medida se emplea la documentación audiovisual para completar grabaciones del día (el 26\% de las noticias emitidas).

Otra característica importante es que los programas informativos diarios la utilizan mayormente como documentación puramente visual. La utilización de la documentación audiovisual es escasa; en nuestro estudio tan sólo un 7\% de las noticias que la utilizaron emplearon también el audio de las grabaciones. En la mayoría de las ocasiones las grabaciones empleadas fueron muy recientes, habían creado polémica, tenían un texto sonoro musical o se trataba de la emisión de noticias elaboradas con anterioridad.

Las peticiones provenientes de las redacciones de programas informativos diarios se responden comúnmente con los fondos documentales que los propios programas han generado. Clasificando las peticiones registradas comprobamos que la mayoría se refiere a imáge- 
nes de personas (más del 25\%) y grupos formales en un contexto no especificado, así como a noticias (ambas en torno al 20\%). En un segundo grupo tenemos peticiones de lugares, animales-cosas-fenómenos naturales y grupos informales (todas ellas en torno al 10\%). El menor número se refiere a conceptos y obras (menos del 3\%).

El análisis semántico y el análisis visual de las grabaciones son fundamentales para dar respuesta a las peticiones del tipo noticia; para el resto de categorías se sustenta únicamente en el análisis del mensaje visual. En estos casos, el análisis semántico ha de utilizarse para informar al periodista del contexto informativo de las grabaciones que recibe.

Si ciertas peticiones requieren un análisis de la imagen muy detallado, el mensaje sonoro, puede recoger únicamente las macroestructuras semánticas. En nuestro estudio ninguna de las demandas registradas requirió un análisis de las microestructuras (discursos, o declaraciones concretas). Además, de las 2.219 realizadas que fueron analizadas tan sólo tres correspondieron a peticiones específicas de sonido.

\subsection{Análisis documental y re- cuperación digital}

En los nuevos sistemas digitales, los periodistas buscan las imágenes por índices onomásticos y, en algún caso, especifican el encuadre, el contexto o la acción que desean. El sistema ha de facilitar la búsqueda de elementos visuales, cuidando de manera especial las imágenes de personas destacadas y de grupos formales porque, como hemos visto, son las más solicitadas y las que requieren un mayor esfuerzo de normalización.

También puede ser el caso, aunque en mucha menor medida, de los nombres de lugares si se está en proceso de normalización lingüísti- ca, o por la propia evolución sociopolítica, o por las normas de estilo del medio. Documentación seguirá siendo un garante de normalización, pero habrá de diseñar instrumentos que puedan ser utilizados directamente por los usuarios.

\section{"Documentación seguirá siendo un garante de normalización, pero habrá que diseñar instrumentos que puedan ser utilizados directamente por los usuarios"}

Ya hemos señalado que una quinta parte de las peticiones que cursa el periodista de informativos diarios se refiere a noticias. La búsqueda de ítems informativos, de acontecimientos concretos, requiere acudir a los índices onomásticos, temáticos y geográficos y una selección de las noticias recuperadas a través de sus títulos. La dificultad que puede conllevar este tipo de búsqueda queda subsanada en gran medida por el hecho de que la mayoría de las peticiones buscan noticias recientes, que en muchos casos ha elaborado el mismo periodista que hace la consulta o, por lo menos, de la que conoce muchos datos. En el caso de tener que utilizar fondos históricos el periodista deberá poder contar con la ayuda de los documentalistas.

El análisis semántico y el visual son fundamentales para poder responder adecuadamente a las peticiones de noticias. El resto se sustenta únicamente en el análisis visual; en este caso, los elementos semánticos informarán al periodista sobre del contexto de las imágenes recuperadas, por lo que en el análisis será suficiente con extraer del mensaje sonoro únicamente las macroestructuras. Los elementos del sonido ambiente, escasamen- te solicitados por sí mismos, serán señalados únicamente cuando sean muy relevantes. Las peticiones de lugares determinados se resuelven a partir de la indización geográfica y onomástica. La búsqueda de obras intelectuales concretas (teatro, cine, videoclips, etc.) con indización temática y onomástica no tiene mayor complejidad.

Para el resto de peticiones se puede ir hacia descripciones en lenguaje natural, ya que la visualización de los documentos es rápida. En estos casos el interés mayor o menor de los documentos y la riqueza visual de sus imágenes incidirán en una descripción más exhaustiva y un mayor número de elementos de recuperación. Las búsquedas de animales-cosas-fenómenos naturales, así como de grupos informales, son mucho menos numerosas cuantitativamente. Las búsquedas de temas amplios y de conceptos abstractos pueden ser laboriosas y complejas, entre otras cosas porque no se conoce a priori lo que se va a encontrar y la estrategia de búsqueda se modifica en función de los resultados que se van obteniendo.

La recuperación será mucho más sencilla y sus resultados de mayor exhaustividad y calidad si contamos con un mapa conceptual, que muestre gráficamente los diferentes conceptos así como su importancia cuantitativa y sus relaciones. Los modelos conceptuales gráficos son sencillos utilizar y su uso se extiende gracias a servicios de gran popularidad en internet. En todos los casos, se tratará de evitar búsquedas infructuosas, cero resultados como repuesta, proponiendo de forma transparente y gráfica conceptos próximos. El usuario deberá poder contar con un buen sistema de apoyo documental en búsquedas amplias, de material histórico o consultas complejas.

Los metadatos asociados permiten la búsqueda y ofrecen, para los contenidos recuperados, la iden- 
tificación de imágenes y voces, las fechas de grabación, el contexto propio (o noticia) y el de emisión (programa donde se ha utilizado y, eventualmente, fechas de emisión). Ahora más que nunca es absolutamente necesario que el periodista conozca el origen (o contexto) y la fecha de grabación de las secuencias recuperadas, ya que son elementos de primer orden para evaluar la idoneidad de esos materiales en el nuevo contexto en el que las quiere emplear. También es muy deseable un control del número y de las fechas de utilización de las secuencias, para evitar que estas "se quemen" y que su uso venga en detrimento de la calidad de los programas.

\section{Digitalización del patrimonio audiovisual, vía para la preservación y la comunicación pública}

Si la producción se lleva a cabo digitalmente en un número cada vez mayor de emisoras, la digitalización de los fondos conservados se asevera una cuestión a medio-largo plazo, y de grades costes económi$\cos ^{1}$. La digitalización es el modo de asegurar la preservación y el acceso a los fondos audiovisuales, sin embargo, requiere unos presupuestos con los que los archivos no cuentan. Para movilizar fondos económicos especiales las emisoras públicas tienen que convencer a los gobiernos y a los ciudadanos en general de la importancia del patrimonio audiovisual.

Pero, como señala Emanuelle Hoog (2005), directivo del INA y el presidente de la Federación Internacional de Archivos de Televisión (FIATIIFTA), a diferencia de la degradación de las catedrales la pérdida del patrimonio audiovisual es invisible para el gran público. El flujo audiovisual cotidiano da la impresión de una infinita riqueza y rechaza la idea de que grandes sectores de memoria colectiva audiovisual están en peligro. El documento de televisión o de radio es percibido como producto de una tecnología accesible inmediatamente y con un simple clic. La restitución de ese documento, entre tanto convertido en archivo, debería de ser posible en los mismos términos. El modo de difusión es tan fácil que el modo de restitución debería ser para muchos igualmente simple e inmediato. Por desgracia, esto todavía es imposible. Por ello, es necesario llevar un mensaje razonado y argumentado, susceptible de beneficiar de medidas perennes para digitalizar las colecciones.

La digitalización es un vector de comunicación y de comercialización, es también un soporte privilegiado de migración, un espacio posible para la conservación del patrimonio. A medida que los fondos se digitalizan se refuerza la campaña de sensibilización, abandona su dimensión puramente intelectual y, operando sobre lo visible, la riqueza y la diversidad, muestra que el acceso al patrimonio tiene sentido y que puede ser democratizado.

La digitalización es la única solución para la preservación de la documentación audiovisual, aunque no resuelva todos los problemas. Según los expertos, nos encontramos en la era de la "migración permanente". La digitalización permitirá migraciones menos costosas, ya que la transferencia podrá

"La digitalización es el modo de asegurar la preservación y el acceso a los fondos audiovisuales, sin embargo, requiere unos presupuestos con los que los archivos no cuentan" ser completamente automatizada. La migración digital será también de mejor calidad, podrá permitir el clon, es decir, la copia perfecta. La digitalización no es un fin en sí misma, sino más bien un medio. El objetivo es la constitución de ficheros eternos y no ya soportes perennes.

Los archivos audiovisuales han sido prácticamente servicios de documentación internos, trabajando para los profesionales de las emisoras. Pocas son las televisiones que tienen un servicio más amplio. El acceso externo y la comercialización de los archivos se han limitado en muchos casos a una reducida lista de productos de catálogo previamente seleccionados. La digitalización amplía la accesibilidad y hace posible ofertar diferentes servicios a públicos diversos: desde la gratuidad, los micropagos, hasta la comercialización profesional de cara a creativos o programadores. Para ello es necesario que el patrimonio audiovisual se abra y se haga disponible a la ciudadanía. Esto que era impensable hace unos pocos años, hoy es perfectamente factible gracias a la digitalización y al acceso a través de internet. Es el momento de que los archivos audiovisuales, en especial los de las televisiones públicas, se replanteen su misión, sus objetivos y desarrollen estrategias de comunicación. Esto es lo que hoy en día empiezan a proponer servicios pioneros como la $B B C$ o el INA (Institut National de l'Audiovisuel).

También la Unesco se interesa cada vez más por ese patrimonio cultural que constituyen los archivos audiovisuales. Desde la adopción en su Conferencia general de 1980 de la recomendación para la "salvación y la conservación de las imágenes en movimiento", su programa Memoria del mundo tiene como objetivo conservar y promover el patrimonio documental.

En las empresas privadas, habrá que convencer a los consejos de ad- 
ministración de la necesidad de digitalizar los fondos audiovisuales. $\mathrm{Y}$ es muy posible que los criterios de estas empresas sean francamente restrictivos, buscando únicamente la rentabilidad económica a corto plazo, con lo que la digitalización no será completa, y se irá produciendo en la medida en que estos materiales se utilicen en la producción o en la emisión. El proceso será todavía más difícil en las pequeñas productoras.

Puede ser un buen momento para plantear y resolver el dilema entre patrimonio (memoria, cultura e historia) y gestión empresarial (rentabilidad económica). La Generalitat ha dado un paso adelante en este terreno con la Ley 22/2005, de 29 de diciembre, de la comunicación audiovisual de Cataluña, que en su artículo 125 instaura el depósito legal para la producción de radio y televisión; hace mención expresa de la digitalización del patrimonio audiovisual público e insta al Gobierno a que promueva la digitalización del patrimonio audiovisual de los operadores privados.

\subsection{El modelo inglés: la $B B C$}

Posee un fondo de archivo muy importante, que comienza a finales de 1880 para la radio y en 1948 para la televisión. En 2005, su volumen se estimaba en 4,6 millones de documentos (600.000 horas de televisión y 500.000 grabaciones de radio), con un crecimiento anual de 130.000 documentos. En 2001 elaboró un plan de diez años para la salvación de sus archivos. Con un presupuesto de 55 millones de libras esterlinas (80 millones de $€$ ), se trataba de transferir una parte de sus fondos hacia soportes digitales: cintas de video en 2" y en 1", cinta de sonido en acetato, Ektachromos, cintas U-matic, etc. Quedan para más adelante las cintas Betacam $S P$ (último formato analógico); el D3 (primer formato digital, hoy en día obsoleto); y todo el material en soporte film, salvo el material Ekta- chromo, que requerirá más tiempo y financiación suplementaria. Desde el comienzo de los proyectos de digitalización masiva, la $B B C$ ha contabilizado un aumento del $40 \%$ en la explotación de los archivos (Wright, 2005).

Desde 2003 se comienza a redefinir el rol del archivo, que pasa a ser entendido como un servicio público. En julio de 2006 publica sus nuevos estatutos, y en este momento se encuentra inmerso en proyectos que hagan realidad ese archivo abierto (Open archive).

\subsection{El modelo francés: el Ina}

En Francia es la entidad responsable de la custodia, preservación y explotación de los archivos de la radio y de la televisión. En 1999 lanza un ambicioso programa de preservación y digitalización. Los tres criterios principales serán: el estado de conservación de los materiales de archivo y su esperanza de vida, las colecciones de alto contenido y la demanda de los usuarios. A partir de 2004, el Ministerio de Cultura y de la Comunicación promueve un plan de digitalización en el cual el Ina ocupa un lugar central. Se calcula que la totalidad del plan de digitalización puede elevarse a 150 millones de $€$ (Amblard, 2005).

En abril de 2006, el Ina abre al gran público a través de internet el acceso a 100.000 grabaciones de radio y televisión, lo que supone más de 10.000 horas de material de archivo. El servicio obtiene un gran éxito entre el público en general y un gran eco en los medios de comunicación. La concepción de la sede web tiene un doble compromiso: por un lado incrementar el volumen de documentos y programas de archivo completamente accesibles, a través de una navegación ergonómica y con un potente motor de búsqueda; y, por otro lado, un compromiso editorial, revalorizando $\mathrm{y}$ convirtiendo el material de archivo en actual y contemporáneo.

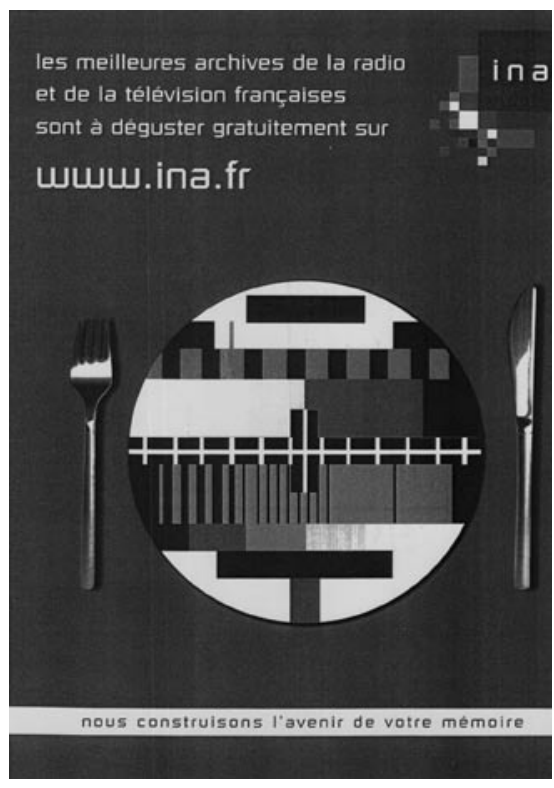

Figura 3. Promoción de los archivos de la radio y la televisión francesa, accesibles en la web del Ina

La web es también el resultado de una importante labor de desarrollo en gestión de bases de datos, en navegación ergonómica, en protección de ficheros y en gestión de derechos. Como señala Emmanuel Hoog (2005, p. 24), es necesario mostrar hasta qué punto el patrimonio es fuente de plusvalías y de valores añadidos en el campo tanto de la investigación y las innovaciones tecnológicas, como en la producción patrimonial, pero también pedagógica, cultural y educativa y en el área de la formación a los oficios de la digitalización.

\subsection{Otras experiencias}

CBC/Radio Canada (que agrupa ocho redes de radio y televisión y cubre el conjunto de Canadá) es un buen ejemplo de la integración exitosa de archivos sonoros y visuales en la sede de un gran medio de comunicación público. La difusión en la web es la continuación lógica del esfuerzo de valorización de los archivos.

En los Países Bajos se crea, en 1997, el Instituto holandés de la imagen y del sonido, $B \& G$, una institución que reúne en un sólo establecimiento el $70 \%$ del patrimonio audiovisual del país. En 2007, in- 


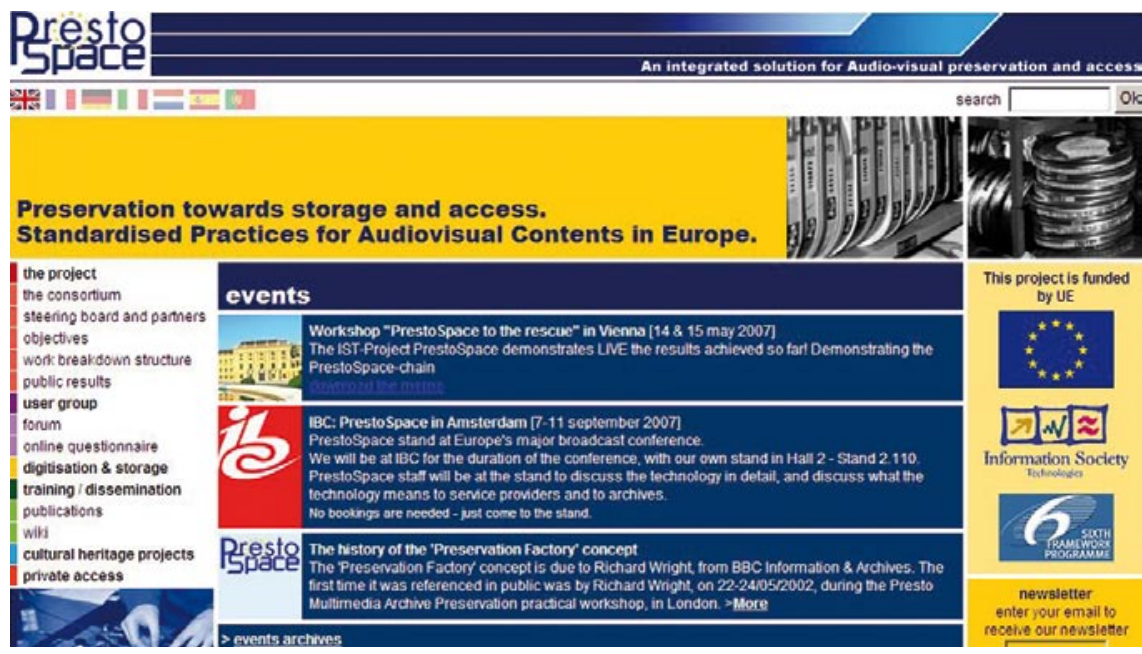

Figura 4. Prestospace

augura su nuevo edificio en Hilversum, pone en línea sus colecciones y lleva a cabo experiencias pioneras de cara al público.

\section{Conclusiones}

Las emisoras de televisión se digitalizan y desarrollan sistemas de gestión de contenidos que les permiten gestionar los activos audiovisuales de una forma integral. Dentro de estos sistemas MAM, los archivos se revalorizan y despliegan diferentes estrategias según las empresas. Las claves del trabajo documental siguen siendo la selección con criterios de archivo, la catalogación especializada, la asistencia en las búsquedas a unos usuarios en cierta medida autónomos, la preparación de materiales con antelación, el trabajo de normalización y, en general, el diseño de los sistemas de información en todos sus aspectos. Nuevas herramientas ayudan al documentalista, simplificando las tareas de análisis y catalogación.

Los usuarios, cada vez más, buscan y recuperan información directamente; las bases de datos y los instrumentos de recuperación deberán adaptarse a sus necesidades y a sus formas de trabajo; tienen que facilitar ayuda a la recuperación. Los nuevos sistemas además ofrecerán estudios de usuarios y de usos de la documentación audiovisual que contribuyan a su mejora.
La digitalización es la única forma de garantizar la preservación del patrimonio audiovisual, pero requiere grandes presupuestos públicos que deben de traer en contrapartida, un replanteamiento de la misión de los archivos audiovisuales, y un compromiso de servicio público, que hoy en día la digitalización e internet permiten. El depósito legal de la producción de radio y televisión, y las consiguientes estructuras de preservación y comunicación, pueden ser una buena vía para garantizar la preservación y el acceso al material audiovisual, tanto de la televisión pública como de la privada.

\section{Nota}

1. La digitalización es muy onerosa: una hora de programa en cinta en 1" o 2" puede costar $85 €$; $50 €$ si se trata de casete de $3 / 4$ ". A esto habrían de añadirse el coste de los nuevos soportes (20 $€$ por un casete vídeo Beta digital), el trabajo de inventariado, el control de calidad, los costes de gestión y los costes de construcción de nuevas unidades de almacenamiento. Una parte de estos costos podrían reducirse con la puesta a punto de útiles que permitan la automatización de algunas tareas; este es uno de los objetivos del proyecto europeo PrestoSpace.

http://www.prestospace.org/

\section{Bibliografía}

Agirreazaldegi-Berriozabal, Teresa. "Audiovisual documentation in the preparation of news for television news programs". En: FIAT/IFTA. Saving and sharing our audiovisual heritage. The age of the television archives. World conference Madrid, 27th-31st October 2006 (versión en castellano de la presentación: "La documentación audiovisual en la elaboración de noticias de los programas informativos de televisión"). http://www.ehu.es/agirreazaldegi/argitalpenak.htm

Agirreazaldegi-Berriozabal, Teresa. El uso de la documentación audiovisual en los programas informativos diarios de televisión. Bilbao: Universidad del País Vasco/Euskal Herriko Unibertsitatea, 1997, 620 p. + anexos (tesis doctoral). ISBN 84-7585-881-3. http://eprints.rclis.org/

Amblard, Marie-Claire. "Le plan de sauvegarde et de numérisation de l'INA". En: Les nouveaux dossiers de l'audiovisuel, 2005, sep.-octobre, n. 6, pp. 56-57

"Archives: les enjeux de la mémoire audiovisuelle». En: Les nouveaux dossiers de l'audiovisuel, 2005, sep.-octobre, n. 6

Conesa, Alicia. "La implementación de un sistema digital para producción y archivo en Televisió de Catalunya”. En: Seminario sobre digitalización de los archivos de televisión. Máster en Documentación Audiovisual. Universidad Carlos III de Madrid, 2005.

http://damocles.uc3m.es:8080/mdoca/noticias/ Alicia_conesa_2005Madrid\%20Sem.pdf/file_ view

Giménez-Blesa, José-Antonio. "Sistemas de producción, gestión y transmisión de contenidos en un entorno digital”. En: López-Vidales, Nereida; Peñafiel-Saiz, Carmen (coord.). Odisea 21: la evolución del sector audiovisual. Madrid: Fragua, 2003, pp. 195-213. ISBN 84-89552-81-9.

Gros, Patrick. "Description et indexation automatiques des documents multimédias: du fantasme à la réalité». En: Documentaliste. Sciencies de l'information. Special image et audiovisuel, 2005, decembre, v. 42, n. 6, pp. 383-391.

Hoog, Emmanuel. «Alerter sur la réalité de la menace». En: Les nouveaux dossiers de l'audiovisuel, 2005, sep.-octobre, n. 6, pp. 23-24.

«Les archives télévisuelles à l'heure du numérique». En: Dossiers de l'audiovisuel, n. 93.

Mariani, Jean-Michel. Infrastructure technique d'une chaîne de TV: Comment les nouvelles technologies transforment l'audiovisuel, de la production à la diffusion. Paris: Groupe Eyrolles, 2003. ISBN 2-212-11353-6.

Vázquez, Maria-Luisa. "The human factor in a world of files". En: FIAT/IFTA. Saving and sharing our audiovisual heritage. The age of the television archives. World conference Madrid, 2006.

Wright, Richard. Annual report on preservation issues for european audiovisual collections (2007). FP6-IST-507336 PrestoSpace Deliverable D22.8-2007 Preservation Status Public, 46 p. Consultado en: 25-05-2007. http://www.prestospace.org/

Wright, Richard. «La numérisation à la $\mathrm{BBC}$ ». En: Les nouveaux dossiers de l'audiovisuel, n. 6, 2005, sep.-octobre, p. 59.

Teresa Agirreazaldegi, profesora titular, Departamento de Periodismo, Fac. CC. Sociales y de la Comunicación, Universidad del País Vasco, UPV/EHU. teresa.agirreazaldegi@ehu.es 